\title{
Institutional Research and Academic Planning in the Context of Higher Education Steering Instruments
}

\author{
Raazia Moosa and Lynda Murray
}

\section{Introduction}

Institutional researchers play a key role in providing data for decision-making within higher education institutions, which includes data to support academic planning. They also provide data for the purposes of public accountability and government steering. In this chapter, we assess the implications for institutional research (IR) of the South African government's steering mechanisms of planning, quality and funding. We do this by exploring shifts in IR practices that support academic planning. These shifts move beyond merely producing reports to meet the minimum reporting requirements, towards enriched reports, which include interpreted and contextualised organisational intelligence, which are more useful to decision-makers than are standard reports.

Two areas of academic planning are discussed: how academic planning strategy is affected by the government's steering mechanisms, and how such steering influences the planning of academic programmes - we thus refer to "strategic academic planning" and "academic programme planning". Strategic academic planning occurs in the higher education sector, as well as within each institution. In particular, we focus on the use of data to support decisions related to academic programme planning at the institutional level, rather than strategic academic planning which overlaps with the strategic planning of an academic institution (see Chapter 6). The central research question we pose concerns the extent to which, if at all, institutional researchers have shifted from generating data for the purposes of reporting to using such data also in academic programme planning and decision-making processes. We provide definitions for academic programme planning and $I R$, and discuss the role IR practice plays, and could play, in providing evidence upon which to base academic programme-planning decisions. We discuss higher education steering models in an international context and focus on government steering policy in South Africa, considering the planning, quality and funding elements. In the second part of the chapter, we report on the results of a survey that was conducted in a number of South African higher education institutions to ask if any shifts are taking place in IR practice towards more specific support for decision-making in academic programme planning. 


\section{Definitions}

In 1976, Fuller (1976) argued that while the desirability for academic planning had increased, its meaning remained imprecise and conceptually ambiguous. He asserted the importance of assessing values and assumptions, clarifying objectives, collecting data, determining institutional priorities and strategies for implementation, and engaging in a continuous and open planning process. Within the context of our study, we offer the following definition: academic planning is planning for the provision of, and resource allocation for, the academic endeavours of an institution. Elsewhere in the world, academic planning can encompass teaching (curricula, programmes, qualifications) and research (and engagement). In South Africa, however, the term tends to be used only for planning related to teaching and learning programmes and qualifications.

Reflecting on tensions between IR as a branch of educational inquiry and research and IR as an administrative and managerial function, Taylor, Hanlon and Yorke (2013) highlighted a shift from 'pure' theoretical work to the 'applied' use of IR as a tool for informing decision making and enhancing quality across a range of activities. Institutional research has been defined in many ways. According to Calderon and Webber IR "is about exploring, understanding and explaining the institution for the institution" (Calderon and Webber 2015:xii). Saupe provides a more nuanced definition of IR indicating the relevance of IR for academic programme planning: "research conducted within an institution of higher education in order to provide information which supports institutional planning, policy formulation, and decision making" (1990:1). Responses to globalisation have led institutional researchers to expand these definitions to include the positioning of institutions to create viable, sustainable and competitive higher education institutions (Calderon and Mathies 2013).

Calderon and Webber (2015) identified a number of challenges that require information, data management and analysis, including the continued massification of higher education, increasing expectations of higher education's contribution to economic development and the continued evolution of institutions of higher education into complex organisations. For higher education institutions to remain relevant in a globalised world, they will need to use data and draw inferences to support decision making. Morest (2009) argues that by creating a culture of evidence, the role of IR practice could shift from providing data for mandatory reporting to a more outcomes-orientated approach in which data are provided for internal functioning in addition to meeting external obligations. It can be expected that reflective practice in IR could emerge from the creation of a culture of evidence (Morest 2009:26).

Voorhees (2005:29) outlines a role for institutional researchers in developing new programmes through collecting and analysing data, posing critical questions and suggesting methods to answer questions. Volkwein (2010) distinguishes between data required for internal and external purposes and maintains that institutional researchers can assist programme-accreditation processes by providing data for assessing whether a programme meets professional standards and for benchmarking programmes. A culture of evidence and continuous improvement is necessary to achieve the outcomes for successful programme accreditation. Accreditation, therefore, creates an opportunity for institutional researchers to provide research-based solutions (Leimer 2009). Volkwein (2010) suggests that IR 
practitioners could play a number of roles in support of programme planning, including the provision of evidence emanating from an analysis of the cost-effectiveness of programmes, from data relating to course and student levels, and from the assessment of faculty performance in teaching, scholarship research and service. By becoming "knowledge analysts" and "knowledge brokers" (Delaney 2009:29), institutional researchers can also expand their role into policy development, assessment, accreditation, programme evaluation and academically focused research studies.

These definitions and descriptions of academic planning and of IR are partly shaped by South African higher education policy. In the next section we elaborate on steering models in an international context.

\section{Steering in International Contexts}

Drivers transforming higher education internationally include globalisation, demographic shifts and rapid technological transformation (Calderon \& Webber 2015). Globalisation forged a new role for higher education that involves greater accountability and, consequently, the need for systems to monitor performance and to understand the impact of national policies (Lange, Saavedra and Romano 2013). Within the framework of neo-liberal market forces and the New Public Management principles, steering mechanisms have emerged internationally, so that national policy frameworks can exert a direct influence on higher education. Ferlie, Musselin and Andrelsani define steering as "the externally derived instruments and institutional arrangements which seek to govern organisational and academic behaviours within higher education institutions. They are usually, but not always, emanating from the state" (2008:326).

Coşkun and Ünal (2013) cite government steering reforms in the relationship between government funding and universities over three decades in countries such as Australia, Canada, New Zealand and the United Kingdom. They argue that these reforms favoured performance-based allocation of resources rather than formula-driven allocation, since performance-based mechanisms (which are considered to be better steering instruments) link resource allocation to output measures. Procedural autonomy characterises the Finnish steering model, which Treuthardt and Välimaa describe as "management by results" (2008). This model includes negotiations between universities and government and between academic staff and university management. The Finnish steering system is indicative of many western higher education systems in which universities are funded primarily through public funds and not by student fees. International models have thus emerged which highlight the role of the government in shaping higher education towards national goals, using performance-based steering mechanisms.

The following section provides more detail about the South African steering mechanisms (planning, quality and funding), and the consequences of these for both strategic academic planning and academic programme planning. 


\section{Steering in the South African Context}

\section{Policy Overview}

In 1994 South Africa's higher education system reflected the country's social inequalities (Badat 2010:2). To change this, the White Paper on Higher Education proposed a system of "cooperative governance" between higher education institutions and government in which "institutional autonomy ... [would] be exercised in tandem with public accountability" with a department that would "drive the transformation of the higher education system through policies and strategies..." (RSA 1997a:30).

In contrast to a programme-based approach, structural differentiation of institutions into rigidly defined types was considered, but was not supported by the National Plan on Higher Education (NPHE) in 2001 as "...it would not be consistent with a programme-based approach if the mission and programme mix of institutions is defined by a predetermined regulatory framework based on structural differentiation between different institutional types" (RSA 2001:54). Differentiation is, however, once again the subject of policy development encompassing not just public and private higher education but also further education and vocational training (see RSA 2014b, DHET 2014b, RSA 2015a, RSA 2015b). The so-called 'binary divide' between technikons and universities was also altered by the NPHE and, by 2005, besides universities, there were two new types of public higher education providers: universities of technology, and so-called comprehensive universities. Of these types, it is the 'comprehensives' that particularly straddle the 'binary divide' of old, since the programmes they offer range from vocationally orientated qualifications, to postgraduate degrees.

The focus on programmes has shaped - even dominated - academic planning in South Africa, although the early conception of 'programmes' has changed. Given the focus on programmes, it is not surprising that they would be the subject of the government's steering instruments or "levers" (Badat 2010:4). Whilst focused on programmes, government steering of academic processes has a broader reach and is accomplished through a "multi-level multi-actor" system, where the actors include government departments such as Department of Higher Education and Training (DHET) and "specialised, semi-autonomous government agencies" (Bailey 2014:10) such as the Council on Higher Education (CHE). Names and acronyms of agencies, actors, levels and projects abound, and include (a) in the context of academic programme planning, the DHET's programme and qualification mix (PQM) and enrolment planning activities, and (b) in the context of quality, the Higher Education Quality Committee's (HEQC) audit and accreditation systems and the HEQC's role in setting standards for the Higher Education Qualifications Sub-Framework (HEQSF) and (c) in the context of funding, the DHET's funding framework and mechanisms.

What is not steered can be as interesting as what is steered; and what is not planned, not quality assured or not funded, can steer intentionally or unintentionally. Some examples are the absence of a programme-planning mechanism for private providers, similar to the public providers' PQM; the decrease in government funding to public providers; and the accreditation roles of professional bodies. 
Because the steering mechanisms cause institutions to state their institutional missions explicitly and to be responsive to national goals, institutions require sufficient staff. Centralised strategic and academic planning, quality assurance and IR units, staffed by professional / support staff, have emerged or been strengthened (Botha 2015:120), because, besides the need to comply with national reporting demands, higher education institutions are required to assess their performance relative to their own goals and to report accordingly (see Chapter 9).

These changes in South Africa were informed by international trends and by the needs of the Southern African region (articulated as long ago as 1981 in the Arusha Convention 2002:4). Programme planning, and quality and funding as steering mechanisms will be discussed separately in the following sections.

\section{Steering Through Academic Programme Planning}

The academic plans of institutions are steered through several mechanisms. Academic planning in higher education institutions should ensure that programmes meet the criteria set by the DHET (formerly DoE), the CHE and HEQC, and by the South African Qualifications Authority (SAQA). The key steering mechanisms and role players in programme planning are the PQMs set by the DHET, the enrolment planning targets agreed between the DHET and institutions, the institutional audits (reviews) conducted by the HEQC, the alignment of programmes with the HEQSF, the accreditation, review and re-accreditation of programmes by the HEQC, and the registration of qualifications by SAQA.

The PQM of a public provider, first determined by the DHET in consultation with each institution in 2002 (Bunting et al. 2010:5), continues to be a key steering mechanism for academic programme planning. Democratic South Africa inherited a higher education system shaped by the racial policies of apartheid. Some of the 36 public higher education institutions, which existed at that time had been created expressly for different races. With the National Plan for Higher Education (RSA 2001), the government initiated a process that lasted until 2005 to change this apartheid landscape through restructuring and through merging several institutions. In the process of reducing the number of public higher education institutions from 36 to 23 (in 2015 three new universities were added), new institutional types came into being: 11 (traditional) universities, six comprehensive universities and six universities of technology. Essential to this process was the determination of the PQM of each institution.

This large-scale project meant that institutions had to develop strategic academic plans to support new institutional missions in concert with their PQMs. Relationships had to change - some academic areas were delinked from one institution and moved to another, whilst some institutions had to merge with others. New academic pathways required academic planners to consider articulation and learner mobility within and across institutions. Systems of different institutions also had to be changed fundamentally or merged. The consequences for IR practice were profound. By merging apartheid-era public providers, by creating new types of universities, and by re-organising the qualifications and programmes of each institution, the government restructured the "size and shape" of South African 
higher education. Henceforth, a public institution's PQM would determine the types of qualifications based on institutional types that the DHET would fund. Universities focus mainly on general formative and professional undergraduate degrees and on postgraduate qualifications on the National Qualifications Framework (NQF), universities of technology offer undergraduate certificates and diplomas focused on careers and degrees in certain areas of strength, and comprehensive universities offer the full spectrum of qualifications, though limited to areas within each institution's range of expertise.

Private providers were not part of the restructuring or PQM exercises although private provision accounted for $9 \%$ of the 950,000 students in South African higher education in 2014 (Botha 2015:115). In the DHET's policy document on differentiation in the postschool education and training system (2014), the PQMs of both public and private provision are mentioned, and PQM as a steering mechanism for programme differentiation is likely to be used alongside steering through funding (DHET 2014b:15) in the context of more focused mission statements (DHET 2014b:12).

Government steering of academic processes, whilst focused on programmes, has a broader reach. Within the context of the current institutional types, all qualifications must comply with the National Qualifications Framework (NQF) (RSA 2008 section 7(b)) and align with the HEQSF (RSA 2014a sections 37 and 38). More recently, the DHET (RSA 2014b; DHET 2014b; RSA 2015a) has proposed further differentiation of institutions that requires academic planners and institutional researchers to provide evidence of national and international comparability informed by benchmarking.

SAQA played a role in the implementation of the NQF, in standards-setting and an outcomesbased approach in higher education, particularly in the first decade of democracy. More recently the HEQC became the Quality Council for Higher Education responsible for the Higher Education sub-framework of the NQF, and thus SAQA's role in higher education has become more indirect.

Planning and funding as steering mechanisms are linked not only through PQM, but also through enrolment plans per subject area determined by the DHET in negotiation with public institutions. The DHET steers the proportion of enrolments per qualification type (e.g. undergraduate or postgraduate) and in terms of subject area. These measures are intended to achieve a goal of the National Plan adopted in 2001 to shift enrolments towards science, engineering and technology (from 25\% to 30\%) and business and commerce (26\% to $30 \%$ ), and away from the humanities (49\% to 40\%) (RSA 2001). The Department of Science and Technology and the National Research Foundation use research funding to public providers as the incentive to achieve this shift. Whilst South Africa needs research and graduates from the sciences, the consequent lack of funding for humanities and social sciences has strategic consequences for academic planning. Institutions may feel steered away from these subjects which could have a detrimental effect on the types of research and the attributes of graduates a young democracy needs (Higgins 2013).

Given the centrality of programmes to the government's view of higher education, the programme accreditation and review system of the HEQC is highly significant. The Higher Education Act, 101 of 1997, created both the CHE and HEQC (RSA 1997b). The Act 
empowers the HEQC to "accredit programmes of higher education" (section 5(1)c.iii) and "audit the quality assurance mechanisms of higher education institutions" (section 5(1)c.ii). Since the CHE published its framework and criteria for programme accreditation in 2004 (CHE 2004a, CHE 2004b), programmes have been accredited on the evidence that they meet particular criteria. The $\mathrm{CHE} / \mathrm{HEQC}$ accreditation system is consistent with its approach to quality assurance that, through self-evaluation, the primary responsibility for quality rests with an institution (CHE 2004a:9). These audit and accreditation systems require institutions to provide evidence of quality-management processes and of resources. Such evidence is largely based on data from an institution's management information systems and from benchmarking, thus rendering IR essential to obtaining and maintaining the accreditation of programmes (Lange et al. 2013:29). This makes IR an important resource for academic programme planning.

The challenge for IR practitioners is to provide the evidence required for programme accreditation and review, whilst reporting to the DHET using a reporting system (HEMIS) which is not entirely aligned to a programme-based approach based on the categories of the HEQSF. Furthermore, centralised IR and planning units often developed from offices that were set up in the 1980s to report in terms of the South African Post-Secondary Education system (SAPSE). SAPSE provided information needed for decisions on funding allocations, but did not use a programme-based approach. When SAPSE was replaced by HEMIS in 2000 the classifications of SAPSE were largely retained. Botha $(2015: 117)$ asserts that the "principles and structure of SAPSE still form the basis of the generation, reporting and analysis of higher education information in South African higher education". To borrow a phrase from Hathaway (1995:536), the structure of the data, based as it is on a non-programme approach, could mean that IR staff "tacitly assume a structure of knowledge" from the data.

IR in support of programme planning, in both public and private providers, has been shaped significantly by the $\mathrm{CHE} / \mathrm{HEQC}$ 's programme accreditation and review system. The HEQC's programme accreditation criteria prescribe "the minimum requirements for programme input, process, output and impact, and review" (CHE 2004b:6-7). HEMIS does not, however, provide most of the information that institutions must submit in order to gain programme accreditation, such as criteria related to programme design, teaching and learning strategy, programme coordination, academic development, assessment and programme impact. The information for only three of the nineteen HEQC criteria is more or less available in HEMIS, namely information on staffing and facilities, and data on student retention and throughput.

Institutions report in many ways to the DHET, including annual progress reports on enrolment plans and institutional plans with pre-determined objectives (see Chapters 9 and 10). These plans need to be aligned with academic programme planning. The steering by government of academic programme planning by public and private providers thus remains central to the government's goals for ongoing transformation of higher education in South Africa. $I R$ is fundamental to academic programme planning. Evidence provided by institutional researchers is necessary for determining the performance of institutions relative to their planning targets; which, in turn, affects an institution's academic size and shape, (Bunting et al. 2010:4-5). Strategic academic planning also requires evidence from outside an institution, for example from market research and from studies of international trends and 
comparability. All these needs require academic planning, and for IR staff to work well with academic staff and other professional / support staff. These data sets are also used to support quality assurance as a steering mechanism, to which we now turn (see also Chapter 8).

\section{Steering Through Quality}

The steering of academic programme planning through quality has largely been guided by the $\mathrm{CHE} / \mathrm{HEQC}$. The mechanism of institutional audits and their prescribed requirements show the range of notions of quality underpinning the $\mathrm{CHE} / \mathrm{HEQC}$ approach. An institution should be fit for its purpose in relation to its mission, should address transformation, exhibit value for money, and show fitness of purpose in relation to national needs and regional and international contexts (CHE 2004c:5). The assurance of quality in the academic sphere takes place at multiple levels in an institution, for example, in some institutions course/module reviews may be done by a department whilst programme reviews may be completed by a faculty. Academic programme planning and quality assurance are interlinked parts of the same cycle of quality improvement. The steps in the cycle can be described as planning, implementation, review, and refinement of plans for the new cycle, based on the aspects that need improvement.

IR units are key to providing much of the data required, including the data for programme reviews. IR units assist academic programme planners with data to meet professional body standards and, by comparing programmes with others nationally and internationally, through benchmarking exercises (Volkwein 2010).

In 2004, the same year the CHE published its approach to programme accreditation, it published its approach to institutional audits (CHE 2004c; 2004d) and embarked on audits of public and some private providers that lasted until 2011. Unlike the CHE/HEQC's programme accreditation approach, the audit system did not prescribe minimum standards. Instead, each institution put forward a self-evaluation report, demonstrating how it met, exceeded, or needed to improve its quality management system against which it was audited. For IR, "[t]hese audits confronted higher education institutions with a range of new data needs" (Botha 2015:120), and it follows that IR and academic planning systems were themselves part of what was audited.

This self-evaluative approach, which emphasised evidence-led self-reflection within a cycle of quality improvement, has had a marked effect on how institutions use their own data. Of particular interest, from an academic planning perspective, is that the CHE/HEQC chose to focus its first cycle of audits (2004-2011) on the quality management of teaching and learning. This emphasis is consistent with the national focus on steering programmes and qualifications because of their crucial role in the development of a democratic South Africa. The CHE/HEQC's audit system placed the responsibility on institutions to meet their own goals whilst being cognisant of national needs.

The $\mathrm{CHE} / \mathrm{HEQC}$ has now moved into its second phase of institutional quality assurance. Again, its focus is on teaching and learning (still in the context of transformation). More specifically, the aim of the Quality Enhancement Project (QEP) "is to enhance all aspects of teaching and learning in order to improve student success." (CHE 2014:ii). IR units are 
expected to provide quantitative and qualitative evidence to support institutional quality assurance as part of the QEP.

Besides government departments, other entities have significant interests in higher education. Professional bodies, some of them with legislative authority, accredit the programmes from which graduates emerge who later apply for membership of the professions. The potential overlap with the HEQC's accreditation role is apparent. The relationship between institutions and many professional bodies can be mutually beneficial and positive for higher education (Briggs, Stark \& Rowland-Poplawski 2003). Ballim, Mabizela and Mubangizi (2014:11431144), however, argue that by prompting regular curriculum review,

... some professional bodies ... have resorted to instruments, such as changes to legislative and regulatory arrangements, funding and financial support agreements and general inter-institutional arrangements, as leverage for directing curriculum and pedagogical structures in universities - often in conflict with the university's mission and in detriment to the quality and depth of student learning.

This broadens the discussion of steering from the narrow sense of government steering, but the instruments of influence are similar, and professional body requirements significantly affect academic programme planning.

Steering of academic areas through quality management continues to be a mechanism used by government, particularly through the $\mathrm{CHE} / \mathrm{HEQC}$. The CHE/HEQC's QEP continues the focus on teaching and learning, rather than on research or community engagement (CHE 2014:i). It is well understood that the primary responsibility for quality rests with the provider, particularly because the HEQC's approach to quality management is based on evidence-led self-evaluation. Good access to data and information generated through IR is important to help staff to evaluate their work on the basis of evidence.

Funding is the third mechanism used by the South African government to steer higher education, and this is discussed in the next section.

\section{Steering Through Funding}

Merisotis and Gilleland (2000) describe steering mechanisms as policy tools developed by the state to encourage higher education institutions to take certain measures to achieve national goals. Government funding is thus a mechanism to encourage universities to meet national goals as stated in the Education White Paper 3 (RSA 1997a), the National Plan for Higher Education (RSA 2001), the National Development Plan (NPC 2013) and the White Paper for Post-School Education and Training (RSA 2014b:10). Inefficiencies in the use of public funds led, however, to the adoption of New Public Management (NPM) principles to improve the quality, effectiveness and efficiency of public services (McCourt 2002). The disbursement of public funds to universities is thus undertaken within the context of accountability, with some discretion in the use of public funds (Polidano 1999).

The South African Higher Education Funding Framework (RSA 2003) is based on a sophisticated management system that monitors the spending of public funds by universities, 
and simultaneously integrates teaching and research-related activities with financial management systems. A Ministerial Statement is released annually, which is governed by legislation such as the Higher Education Act (RSA 1997b and as amended) and the Funding Framework for Universities (RSA 2003), and guides the allocation of funds to universities. Public accountability for various grants warrants annual reporting in terms of how national policy goals and priorities have been met, how these funds have been spent and what was achieved using these resources. These funds are not intended to support all the expenses of universities and consequently the Ministerial Statement on University Funding requests universities to implement "efficiency measures" and to generate extra funding outside the public purse. Suggested measures of interest to academic planning include collaboration amongst universities, and the generation of third stream income (DHET 2014a).

A goal-oriented, performance-based funding system (Carrim and Wangenge-Ouma 2012) is used by the South African government to steer universities towards the achievement of policy priorities such as access and success based on approved plans. Hence, a portion of the higher education budget is allocated to specific performance measures such as approved enrolment places, success rates and the percentage of disadvantaged students admitted. Steering is achieved through funding instruments such as block and earmarked grants. Block grants are allocated to universities and comprise approximately $70 \%$ of the government's

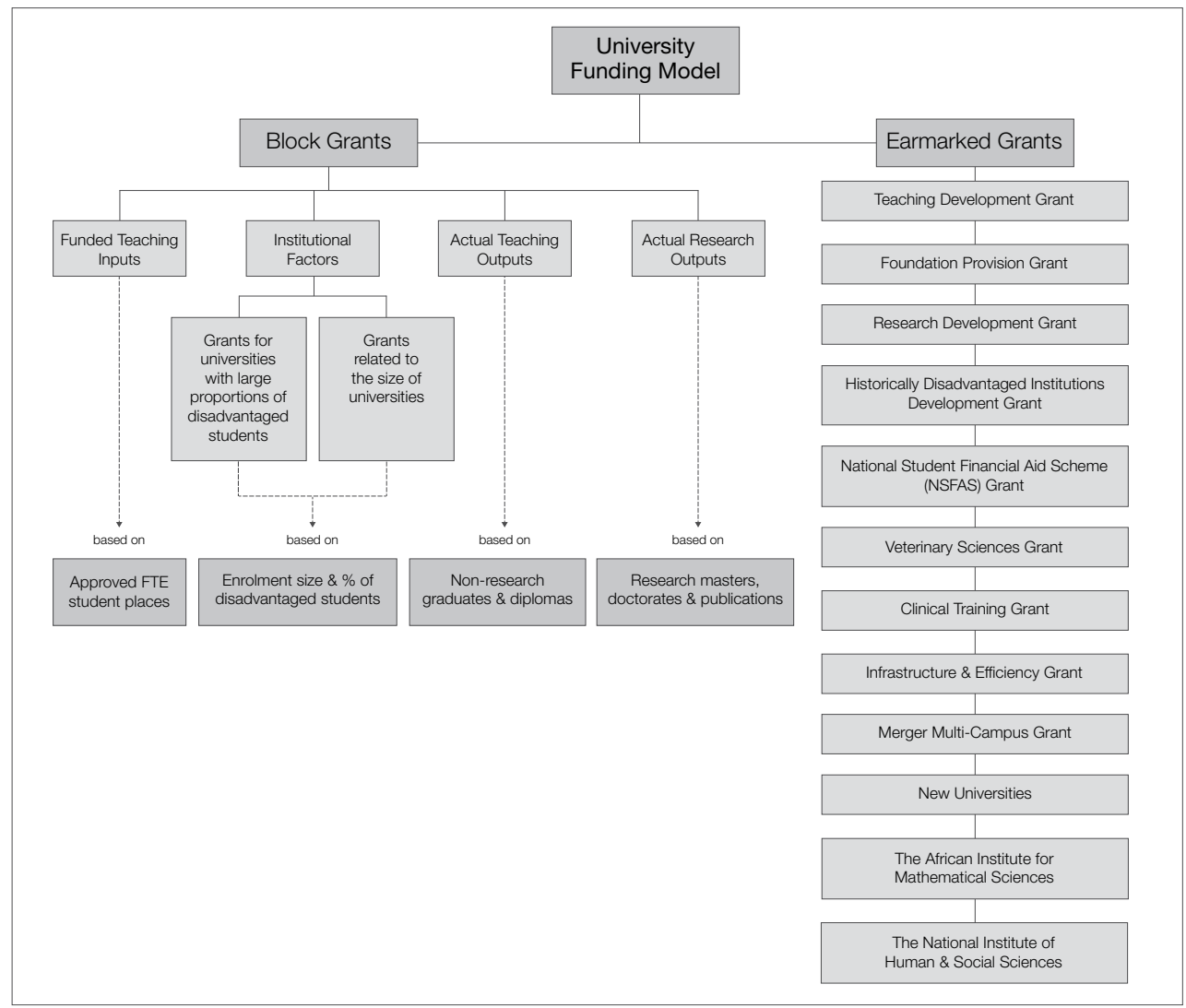

Figure 1: University Funding Model (adapted from DHET 2014a) 
budget for universities (DHET 2014a). These are council-controlled funds, which can be used at the discretion of the university management for operational costs (see Figure 1).

In addition to the block grants, earmarked grants such as the Teaching Development Grant and the Foundation Provision Grant (see Chapter 11) are allocated to universities for specific purposes, and thus serve as more effective central steering instruments since they are targeted and measure performance towards meeting national priorities (Merisotis and Gilleland 2000).

In institutions, institutional researchers are often responsible for the block grant calculations and external annual reporting using data from HEMIS. This reporting ensures that programmes receive government subsidy. When planning a programme, decision-makers should consider the cost of a particular programme. Because of the transparency in the funding formula, it is possible for institutional researchers to calculate how much subsidy a programme could generate. Such calculations are, however, challenging because HEMIS uses subject-matter categories rather than categories derived from a programmes approach. In addition, higher education institutions will only receive funding for programmes that they offer that have been accredited (see the section on steering through quality above). Volkwein (2010) suggests providing course/module level data and conducting cost-effectiveness analyses as possible roles that institutional researchers could play in programme planning.

A discussion of steering through funding should mention the direct and indirect decrease in government funding to public providers. Salmi (2012:4) states that "South African universities are well-off compared to most countries in the region, but at $0.6 \%$ of GDP South Africa's spending on tertiary education is far below the OECD average of $1.3 \%$ ". Furthermore, while

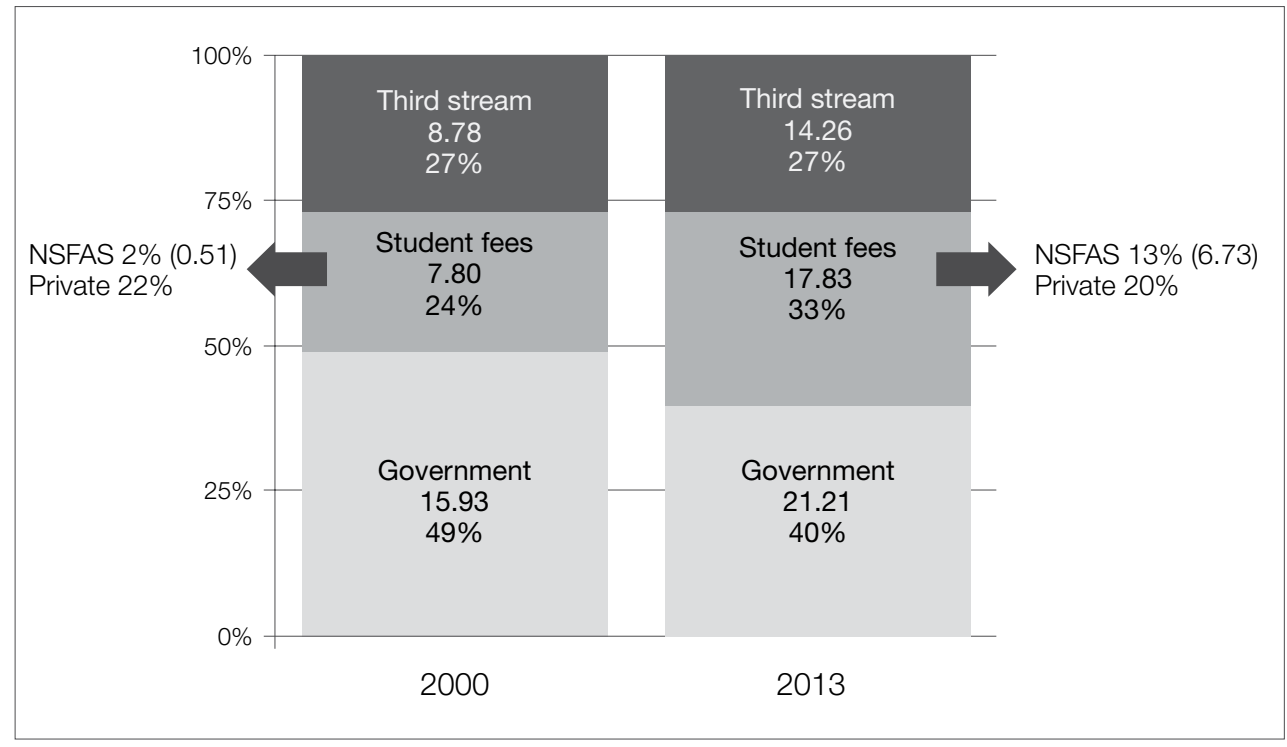

Figure 2: Streams of university income (ZAR billion) in 2000 and 2013

Adapted from Cloete, Sheppard and van Schalkwyk 2016:29 
government spending has decreased from $49 \%$ of the total income of universities in South Africa in 2000 to $40 \%$ in 2013, the proportion of income from student fees has increased from $24 \%$ to $33 \%$ over the same period (see Figure 2).

Insufficient government funding for universities and increases in student fees prompted the student fees crisis in October 2015 (Habib 2016). This has obvious consequences for academic planning in terms of student throughput and enrolment, particularly for financially needy students.

The sustained pressure created by insufficient government funding over many years has contributed to several institutions deciding to change their 'business models', for example by establishing companies to develop alternative income streams. Hence, academic programme planning and IR units have needed to adjust their systems in line with the new business models of their institutions. This illustrates an institutional response to steering which impacts on funding, programme planning and quality. As such, an institution's selfdirection is crucial and will be elaborated upon in the next section.

\section{External Steering and Self-Direction}

During the years of South Africa's democracy since 1994, IR has helped higher education institutions to cope with several, large and often simultaneous changes that went to the heart of the academic realm. Academic freedom is guaranteed in South Africa's Constitution (RSA 1996: Section 16(1)(d)). How this right extends to academic institutions, whether it is balanced with other rights or nuanced by the responsibility of accountability, continues to be debated. But, academic freedom is fundamental for academic work and hence must inform academic planning.

External pressures on institutions include those from government to meet its national goals. Institutions may agree with the goals even though they may disagree with the contributions expected of them. Government, understandably, sees higher education institutions as important instruments in the country's development, whereas public universities do not necessarily see themselves as organs of the state.

The many new, and simultaneously introduced, reporting and accountability regimens imposed by the state and related actors (Bundy 2006:9, Badat 2013) have required many institutions to appoint more professional and support staff in strategic and academic planning, quality assurance and IR (Botha 2015:118). The increase in such staff has not always been well received. There is the perception that managerial groups are "aligning with governments' drive for accountable university performance, towards a new social compact in support of functional - rather than substantive - autonomy. This is considered to hold a potentially serious threat to scholarly freedom and academic rule" (Du Toit 2007:5). Staff appointed in academic planning and IR units are often considered to be part of these managerial groups.

The changes in institutions because of external pressures are not all, directly or indirectly, the result of government steering. Other influences are international higher education practices such as rankings and benchmarking (which can lead to mimicry) and pressures from 
professional bodies and other stakeholders for curriculum change. IR staff and academic planners need to be aware of this to avoid unnecessary imitation or isomorphism (Badat 2010:9-13), whether at the institutional or curriculum level.

These external factors mean that academic planning and IR need to be conducted with a broad outlook, and with the support of other functions such as costing models and market research, to take this variety of pressures into account. Government steering of academic programme planning through planning, quality and funding has significantly shaped the South African public and private higher education system. The methodology for how these conceptual frameworks in the context of steering could be applied to IR and academic programme planning are explored in the next section.

\section{Methodology}

A qualitative survey was conducted during 2015 amongst several South African higher education institutions. The purpose of this study was to gain insight into the experiences of the support that institutional researchers provide to academic planners. This purpose makes a qualitative survey appropriate (Jansen 2010:2). The aim was to investigate the extent to which shifts in IR practice affect decision making on academic programme planning within the context of higher education steering. Our research question examines the extent, if any, to which institutional researchers have shifted from generating reporting data to using such data in the academic programme planning and decision-making process?

A qualitative research approach informed a survey design that guided the collection of data using a questionnaire. A non-probability sampling strategy (Roberts-Holmes 2011; Creswell 2012) using a combination of purposive and convenience sampling was used to select the sample. On the one hand, a convenience sampling strategy allowed easy access to Directors of IR and institutional researchers who were available to participate in this study. On the other hand, a purposive sampling strategy enabled the selection of public and private providers representing different institutional types. Using the 2014 database of higher education institutions which had attended the annual forum of the Southern African Association of Institutional Research (SAAIR) in 2014 to select the sample, meant that the total database consisted of a population of 22 South African higher education institutions i.e. 19 public universities and three private institutions (institutions in other Southern African Development Community - SADC - countries were excluded). Our sample was of institutional researchers from 15 higher education institutions, including five traditional universities, four universities of technology, three comprehensive universities and three private institutions. A convenience sampling strategy ensured that the contact information for the Directors of IR within the samples was obtained from the 2014 SAAIR database. Care was thus taken in the selection of the sample to ensure that its characteristics matched higher education institutional types in South Africa (McMillan and Schumacher 2010).

After the pilot testing of the questionnaire, it was sent to the institutional researchers. 11 responses were received, representing all the institutional types in South Africa: four responses were received from universities, three from comprehensive universities and two each from universities of technology and private higher education institutions. 
The participants in the survey who worked in institutional or academic planning units constituted the largest group (45\%). Those who reported that they worked in IR units formed $27 \%$ of the participants and were equivalent in number to those who straddled IR and planning units (see Table 1). At some universities, the institutional researchers felt that the planners were better suited to respond to the survey and the survey was forwarded to those individuals.

Table 1: Designation of Participants

Designation of Participants

Number

Planning (Institutional and Academic)

\begin{tabular}{|l|c|}
\hline Directors: Planning & 1 \\
\hline Directors/Heads: Academic Planning and Quality Assurance & 3 \\
\hline Institutional Planning Officer & 1
\end{tabular}

Institutional Research

\begin{tabular}{|l|r}
\hline Institutional Researcher & 3
\end{tabular}

Institutional Research and Planning

\begin{tabular}{|l|r}
\hline Directors: Institutional Planning and Research & 1
\end{tabular}

\begin{tabular}{l|l} 
Vice Rector Academic & 1
\end{tabular}

Director: Monitoring, Evaluation and Research

The responses were analysed using ATLAS.ti to code and elicit themes from the data. According to Jansen (2010), qualitative surveys as a research design are often misunderstood. Explicating the limitations of this study is thus warranted. One of the limitations of this study is that it is context-dependent and thus limited in that not all public and private providers were represented at the SAAIR Annual Conference in 2014. Although all the institutional types are reflected in the population, the low response rate is a limitation since it has implications for reaching saturation within this study. Reaching saturation in a qualitative survey is, however, according to Jansen (2010) an empirical issue, which relates to the aim of the study and diversity of responses provided. Saturation in this study was reached because of the various responses received from all the institutional types. Despite these limitations, the responses indicated that a qualitative survey design was appropriate for a study that seeks to investigate how shifts in IR practice have affected decision making in academic programme planning. We elaborate on this in the next section.

\section{Shifts Towards Decision-making Support for Academic Programme Planning}

\section{Contextual Definitions for Academic Planning and Institutional Research}

Participants in the survey were asked how their institutions defined academic planning and IR. Responses revealed different conceptions of 'academic planning', yet with common elements. 'Academic' in the South African higher education context is generally understood to refer to teaching and learning, research and community engagement (if the community 
engagement activities are knowledge-based and related to the other two academic functions). Few participants, however, considered research or community engagement to be part of 'academic planning' in their institutions.

The different institutional types offered various definitions for academic planning, including the following:

"Academic planning in our institution is regarded as a process of assisting academics when developing new programmes, i.e. Programme and Qualification Mix, course budgeting, programme benchmarking, academic staff recruitment, programme approval, qualification review". [Private Institution]

“...[the institution] doesn't define it formally. In practice it covers enrolment planning, PQM (and its development), programme benchmarking, programme approval, qualification review, campus PQM development".[University]

"There is no institutional definition of academic planning, and there is no single Academic Planning entity.The academic planning activities, responsibility for which are across the university, include enrolment planning and management (including staff provisioning), PQM, programme approval, qualification reviews (including viability and sustainability), academic structures, elearning offerings, development of performance indicators - success rates, graduation rates, etc.". [University of Technology]

The findings from this study show contextual definitions for IR which differed amongst institutions. Both quantitative and qualitative research is undertaken by institutions to provide evidence-based planning and decision support to management. Although some responses indicated that there was no university or official definition of IR, it was nonetheless being conducted.

"We have no definition of IR at present. We started in earnest earlier this year [2015] with a project to launch Institutional Research in an integrated and expansive way, so the concept is being debated and developed. This is not, however, to say that no IR has been conducted (see further below). [UoT]

In the absence of an official definition of IR, some universities offered activities at different management levels within an institution such as:

"The University does not have an official definition for "institutional research", but as such the term could include a range of activities at different management levels within the institution: any data analysis done by staff or students that leads to actionable information (or "business intelligence") for decision-making or selfinsight, could potentially be classified as "institutional research". [University]

Definitions for IR included both an internal supporting function as well as an external national reporting function. Definitions of IR with an internal reporting focus emphasised the collection, analysis, interpretation and dissemination of information to support decisionmaking at various levels of the institution, monitoring of interventions, institutional planning, 
scenario-building, data on programmes offered and policy development, and support for decision-making related to the evaluation of existing procedures. Some institutions also highlighted course/module fee analysis, research studies and the critical appraisal of the state of that particular university in relation to its strategic objectives and priorities in order to understand how change takes place at the university.

Institutional research is "research conducted internally to the university designed to support decision making, the monitoring of interventions and the critical appraisal of the state of the University in relation to its strategic objectives and priorities. Institutional research is fundamentally an investigation of how change takes place at the university." [University]

"... the foundation and rationale for all decisions and actions aimed at realizing the core-business of the university." [Comprehensive University]

“... any data analysis done by staff or students that leads to actionable information (or "business intelligence") for decision-making or self-insight, could potentially be classified as "institutional research." [University]

"Institutional Research refers to any intended enquiry for better understanding of institutional dynamics as well as external environment/s for better management decision making". [UoT]

"Institutional research includes quantitative and qualitative research and analyses about the institution for the institution to provide evidence-based planning and decision support to management". [Comprehensive University]

Definitions of IR with an external reporting focus involved national reporting and are concerned with issues, trends and patterns in the higher education system. The following example illustrates how institutions define IR in terms of its external reporting emphasis:

"The collection, interpretation and dissemination of information with respect to the programmes offered in or planned for the Schools and the students enrolled in these programmes. This includes research on applications, enrolments and offers to prospective students. The IR person is also responsible for DHET and [other] reporting and registrations on the National Learner Data Base. [Private Institution]

Saupe (1990) and Delaney (2009) refer to IR in terms of policy development. Only one university in our survey, however, highlighted the policy development aspect of IR. Because of the lack of emphasis on the development of policy within the context of steering, this could thus become a function that institutional researchers may wish to strengthen in order to provide support to decision makers who are confronted with internal and external policy development in the realm of academic programme planning.

These contextualised definitions of IR and academic planning have largely influenced the support provided for academic programme planning as evidenced in the next section. 


\section{IR Support for Academic Programme Planning}

The findings from the survey indicated that activities performed by IR units to support academic programme planning range from managing student data to analysing and interpreting information for enrolment and programme planning. The results demonstrate that most IR activities are undertaken to produce data to support management information and transformation, monitoring and evaluation and quality advancement requirements. Within the context of national steering, however, Maassen and Potman (1990) acknowledge that IR units should fulfil these functions and they argue that the responsibility for monitoring and quality should rest with institutions.

IR support for the management information and transformation aspects of academic programme planning is provided by producing data at an institutional and programme level. At the institutional level, management information is produced to support the data requirements for the institution's PQM, enrolment planning, spatial planning, throughput and retention studies, financial modelling and analysis and transformation planning requirements. The institutions surveyed in this study reported that, in the decade since the implementation of the $\mathrm{CHE} / \mathrm{HEQC}$ programme accreditation system, the support provided by IR units to programme planning activities has been enhanced. Examples are:

"[d]ata for enrolment planning, throughput and retention studies, institutional benchmarking, internal satisfaction and other surveys, studies on issues ... (in the higher education sector)" [University].

"...by providing information for the following areas of academic planning: Strategic Planning; Management Information; Transformation, Monitoring and Evaluation; Quality Advancement; and Academic Planning. Data is provided for: enrolment planning, course budgeting for course design, benchmarking for programme approval, analysis of data for course/ programme/ qualification review etc." [Comprehensive University].

At the programme level, management information is used to undertake needs analyses based on national skills gaps, costing and budgeting for course/module design, course/module fee analyses and benchmarking for programme approval and reviews. Because of the various approval structures within an institution, the assessment of the viability of new programmes is devolved and takes place at the faculty level. While course/module fee analysis is an aspect of reporting, some institutional researchers reported providing data from financial modelling to support decisions regarding course/module costing and budgeting. This is illustrated by the following responses:

"Faculty managers do course costing and budgets in anticipation of the possible introduction of new programmes and/or modules". [University]

"Market research; needs analyses; student evaluations; student and graduate surveys; monitoring of student success (through the academic year); tracking of student pass rates; monitoring of progress towards meeting institutional academic goals". [Private Institution] 
While course/module costing and budgeting are undertaken, some public universities stressed that a common practice has been to plan and subsequently offer programmes in the absence of data in terms of which the costs of a programme could be calculated. Seymour (2002) argues that fragmentation in planning, as well as the research to support planning and programme review, is detrimental to an institution.

Within the context of internal and external steering, monitoring and evaluation activities to support academic programme planning include monitoring progress towards meeting institutional academic goals, environmental scanning to keep the university abreast of national and international trends, student evaluations of modules, support for teaching and learning, assessments of internal satisfaction, as well as a range of other surveys, including graduate destination studies, tracer studies and employer satisfaction studies.

In order to support the requirements of quality advancement for programmes, the results indicate that routine functions included the analysis of data for course/module and programme reviews, student evaluations of tutors (face-to-face tutors and e-tutors), external accreditation processes and programme benchmarking. In terms of quality advancement, Leimer (2009) contends that accreditation necessitates a culture of evidence and continuous improvement. Our survey showed that IR units at private higher education institutions also provided data for programme profitability, awards and bursaries, for billing on student accounts and for graduation ceremonies.

The institutions surveyed reported that data are routinely used in academic programme planning for ad hoc queries, programme reviews and compliance reporting. Uneven shifts are however, experienced in generating data for academic programme planning purposes. For example, limited financial resources and high workloads for academic, and for professional and support staff mean that impact studies, market research, graduate tracking and graduate destination surveys are areas where support for academic programme planning could be improved. Only a few tracer studies are conducted on an ad hoc basis and are not a routine IR function. Both public and private institutions indicated that:

"More can be done to undertake employer surveys as a way of triangulating results". [Comprehensive University]

"...We do not provide impact studies really. We do programme review only at the level of the academic value of the programme ... We rely a lot on opinion expressed by external members of our School Boards.The concern is that it is guesswork about market gaps because our market research needs to be improved.It is alright for the general lower level qualifications but the higher more specialised qualifications need to be more tightly focused and attuned to market needs". [Private Institution]

Graduate destination surveys and tracer studies are significant since they are a means of providing decision makers on academic programme planning with data on the employability of graduates and the appropriateness of programmes that are offered. The responses of two institutions emphasised the need for data from impact studies, graduate destination surveys and market research to support academic programme planning. 


\section{IR in support of alignment with National Priorities and the achievement of Institutional Goals}

In addition to providing data for management information and transformation, monitoring, evaluation and quality advancement, some participants in the survey signalled that they also provided data for strategic academic planning. To this end, their institutional vision and strategies were closely aligned to the National Development Plan and they use data from needs analyses of national skills gaps to provide data support to meet national priorities. This was, however, also identified as a gap in the support that IR units provided. This is succinctly stated by one university: "Support for national goals and national priorities is very important in terms of new programmes and the gaps in our existing suite".

Two private providers indicated that the use of market research and the inputs from advisory boards help them plan their programmes in such a manner that these meet workplace expectations. Most public and private providers indicated that academic planning required market research, attention to government-identified national skills priorities and scanning of international trends, though many did not regard such outward-focused work as part of an IR unit's responsibility.

Most of the participants indicated that IR units provided support for planning with a view to the achievement of institutional goals. A comprehensive university highlighted their focus on addressing institutional strategic challenges as well as sectoral challenges stating that:

"Institutional research aims to proactively support strategic and institutional planning and inform management decision-making through institutional research studies and conducting analyses that generate timely and appropriate information to facilitate decision-making, and evidence-based strategies that contribute to sustainable institutional effectiveness, and address strategic challenges faced by the University in particular, and by the Higher Education sector in general". [Comprehensive University]

The $\mathrm{CHE} / \mathrm{HEQC}$ 's audit system places the responsibility on higher education institutions to set and meet their own goals whilst being cognisant of national needs. Within the context of external steering, IR units therefore need to show how well the provider is achieving its own aims, in the midst of the challenges that confront them.

\section{Challenges Confronting IR}

Our survey indicated that capacity challenges have affected the performance of institutional researchers. The major gaps in some institutions relate to the integrated provision of data as it relates to academic programme planning and human resources, finance and facilities planning. These gaps limit the abilities of decision makers to plan and approve programmes based on evidence. Despite these challenges, the automation of standardised reports and the use of dashboards in most institutions has enabled some institutional researchers to shift their focus from only generating reports to interpreting data and making data more accessible for making decisions on academic programme planning. One university has captured this as: 
"The IR function is seen as a dynamic and essential part of evidence-based/driven/ informed decision-making and as such it continuously shifts towards student success analyses; not only capturing and reporting data, but also generating business intelligence and empowering not only staff, but also students with selfinsight and improved (organisational and personal) learning" [University].

Another challenge facing IR units is the co-ordination and alignment of support for academic programme planning. Institutional researchers also pointed out that they are expected to produce comprehensive analytical reports in addition to their reporting activities. Ineffective and insufficient co-ordination and alignment of the support from IR units for academic programme planning does, however, remain a challenge. To address this, many institutions have opted for the co-ordination of data from one central unit. Critical feedback from decision-makers on reports provided by institutional researchers and the need to close 'the feedback loop' are suggestions that emerged from the survey:

"Sometimes institutional researchers are not entirely aware of how their reports are used to make decisions or inform practice. For example, the results of student module evaluations are shared with module coordinators, Heads of Schools, Deans and other decision-makers. Decisions or actions emanating from their interactions/meetings, if any, are left to their discretion, without any expectation that definitive outcomes are necessary and need to be fed back to IR. Therefore, while our reports could lead to concrete decisions/practices, we might not be aware of them" [Comprehensive University].

Staff capacity in institutions to conduct high level academic planning and IR vary for many reasons (see Chapter 5). Nevertheless, most institutions reported that the challenge for institutional researchers is to shift beyond merely producing reporting documents, which meet the minimum reporting requirements, to generating enriched reports, including interpreted and contextualised organisational intelligence, that are more useful to decisionmakers. The reporting role seems to be the default position when resources are scarce (see the findings reported in Chapter 4). One university reported a shift back to reporting as a consequence of pressure of work and insufficient staff capacity.

"With a director carrying responsibility for IR, reporting and QA and two researchers ....and in the absence of a dashboard, the unit is stretched. So the new reporting regulations have turned the tide back to generating reporting data" [University].

It does not bode well for institutional self-direction if the default position for IR is external reporting at the expense of internal queries.

In light of a need to respond to internal ad hoc and standard queries, integrating data sources across information systems in the university is a challenge for institutional researchers. Our survey indicates that IR units have a commitment to continuous improvement in the support that they wish to provide to academic programme planners. Institutional information systems are also continuously upgraded to meet user requirements, which include upgrades to make better provision for the needs of academic planners, in particular the need for information on the financial viability of programmes. This is evidenced by the following response: 
"The IR Office has just developed, ... another system of "Academic size and shape models" (there are three models - a Forecasting Model, an Affordability Model, and an Academic Planning Model) ...to provide academic leadership with dashboards to assess the strategic and financial viability of their faculties/ schools/ departments/ programmes" [Comprehensive University].

A private provider emphasised the need to train academic staff to use student information for their ad hoc queries to enable them to evaluate their courses/modules. A university of technology, however, pointed out that its "very disparate IR related sources" hamper academic staff from integrating information.

A private provider stated that:

"IR is done using the sophisticated student management system... Reporting is the smallest part of what the institution does in IR... information [from the student management system] is really used a lot by academics on an ad hoc basis for 'micro'-level questions, and up to higher levels.... Most IR is not used for any formal reporting - one won't find it written up - the data are accessed to answer ad hoc questions. It is a self-reflexive form of interrogation of what we do. The IR system is also used for routine reviews and reports, and for compliance reporting, but is most often accessed for informal queries. ... We never used to be so close to the data but we changed the student system precisely so we could be" [Private Institution].

A major gap in some institutions was identified as the effective use of dashboards and integrating data sources at the systems level. Staff capacity constraints and the limited capacity to undertake market research and employer and graduate surveys were also viewed as challenges facing IR's support for academic programme planning. The opportunity thus exists for these challenges to be incorporated into future practices.

\section{Emerging Practices}

The functions that are required to support strategic and academic programme planning are not always well understood by institutional researchers. Emerging practices to address data for making decisions on academic programme planning include impact studies, more systematic graduate destination surveys and market research, the integration of data sources at the systems level, and the provision of data for academic policy development.

The identification of scholarly research by IR units was identified in the survey as an emerging practice. Moreover, our survey showed that professional/ support staff and academic staff do not always consider each other's work with as much thoroughness as perhaps they should. On the one hand, a university reported that documents produced by institutional researchers and academic planners "are rarely interrogated and tend to be accepted uncritically" by academic structures. On the other hand, only a few institutional researchers mentioned that they consult academic publications as sources of information for IR. Perhaps this indicates, firstly, a need for some IR staff to have a better understanding of the culture of higher education and its institutions - the "tier 3 contextual intelligence" (Terenzini 
1993:5) - since it will allow institutional researchers to gain an awareness of internal and external mechanisms at sectoral and institutional level. Secondly, it indicates a need for some academic staff to have a better appreciation of the roles of professional/ support staff. Scholarly research could position institutional researchers in terms of what Delaney (2009) regards as "knowledge analysts" and "knowledge brokers". The use of scholarly research that focuses on the university context and feeds into decision-making to inform improvement is thus emerging, and is part of the shift from a focus on merely reporting, to the application of data to support decision making for academic programme planning. The shifts experienced in IR to support academic programme planning as well as emerging practices can largely be attributed to internal responses to globalisation and external steering from the government.

\section{Concluding Reflections}

Shifts in IR to support making decisions on academic programme planning are evident in the South African higher education system. Many of these shifts are associated with steering through government's planning, quality and funding mechanisms. Other shifts are not aligned with steering, because IR practitioners have also responded to factors affecting academic programme planning, such as global teaching trends, the skills needs of employers, or a higher education institution's decision to generate more income through short courses. Nevertheless, in 22 years of democracy, direct government intervention through steering has profoundly changed South Africa's higher education system. With the government's continuing focus on the steering of academic programmes - an understandable focus given how central higher education is to South Africa's transformation goals and given that programmes go to the heart of the academic realm - academic programme planning, and hence IR, needs to remain alert to the impact, positive or negative, of government steering. Academic planning and IR should also continue to identify pressures on academic freedom internally and externally. Whilst higher education institutions are confronted by challenges, reflective practices have enabled shifts to take place from a focus on reporting to using data also in the application of making decisions for academic programme planning. Within the context of steering, all higher education institutions surveyed reported that IR is essential not only for reporting to government, but also for providing evidence-led, self-reflective academic programme planning in pursuit of an institution's own goals and the national priorities.

\section{References}

Arusha Convention on the recognition of qualifications in Higher Education in Africa. 2002. Regional convention on the recognition of studies, certificates, diplomas, degrees and other academic qualification in Higher Education in African States. Adopted at Arusha on 5 December 1981, revised at Cape Town on 12 June 2012. UNESCO.

Badat, S. 2010. The Challenges of Transformation in Higher Education and Training Institutions in South
Africa. Paper Commissioned by the Development Bank of Southern Africa. PMid:20357300

Badat, S. 2013. Theses on institutional research and planning at universities. South African Journal of Higher Education 27(2):296-308

Bailey, T. 2014. The Roles and Functions of Higher Education Councils and Commissions in Africa: A Synthesis of Eight Case Study Reports. Cape 
Town: Centre for Higher Education Transformation (CHET).

Ballim, Y. Mabizela, S. and Mubangizi, JC. 2014. Professional bodies and quality assurance of higher education programmes in South Africa: Towards an appropriate framework. South African Journal of Higher Education, 28(4):11401155.

Botha, J. 2015. Institutional Research in South Africa in the service of strategic and academic decision support. In Webber, K. \& Calderon, A. (eds.), Institutional research and planning in higher education. New York: Routledge. 115-127. PMCid:PMC4667419

Briggs, CL, Stark, JS and RowlandPoplawski, J. 2003. How Do We Know a "Continuous Planning" Academic Program When We See One? The Journal of Higher Education, 74(4):361-385. http://dx.doi.org/10.1353/jhe.2003.0028

Bundy, C. 2006. Global patterns, local options? Changes in Higher Education internationally and some implications for South Africa. In Kagisano: Ten Years of Higher Education Under Democracy: (4). Pretoria: Council on Higher Education.

Bunting, I., Sheppard, C., Cloete, N. and Belding, L. 2010. Performance Indicators in South African Higher Education 2000-2008. Summary Report. Centre for Higher Education Transformation, Wynberg, South Africa: Compress. Dsl.

Calderon, AJ. and Mathies, C. 2013. Institutional research in the future: Challenges within higher education and the need for excellence in professional practice. New Directions for Institutional Research, 157(Spring):77-90. [Retrieved 13 May 2015] http://doi.org/10 1002/ ir.20040. http://dx.doi.org/10.1002/ ir. 20040

Calderon, AJ., and Webber, KL. 2015. Institutional research, planning, and decision support in higher education today. In Webber, K. \& Calderon, A. (eds.), Institutional research and planning in higher education. New York: Routledge.

Carrim, N. and Wangenge-Ouma, G. 2012. Higher Education in South Africa: A report of Higher Education of South
Africa. British Council South Africa, Cape Town.

Cloete, N., Sheppard, C. and van Schalkwyk, F. 2016. Fees and Sustainable Development - Moving the Higher Education Fees Debate from Ideology to Evidence. Centre for Higher Education Transformation (CHET) [Retrieved 20 June 2016] http://www.chet.org. za/files/resources/Fees\%20and\%20 Sustainable\%20funding\%20РPT\%20 Final\%2011May16.pdf.

Coşkun, A, and Ünal, G. 2013, Higher Education in Turkey: Trends Towards Self-Steering Public Universities, Journal Of Higher Education / Yüksekögretim Dergisi, 3(1):40-47.

Council on Higher Education (CHE). 2004a. Framework for Programme Accreditation. Pretoria, South Africa: Council for Higher Education.

Council on Higher Education (CHE).2004b. Criteria for Programme Accreditation. Pretoria, South Africa: Council on Higher Education.

Council on Higher Education (CHE). 2004c. Framework for Institutional Audit. Pretoria: Council on Higher Education.

Council on Higher Education (CHE). 2004d. Criteria for Institutional Audit. Pretoria: South Africa: Council on Higher Education.

Council on Higher Education (CHE). 2014. Framework for Institutional Quality Enhancement. Pretoria: Council on Higher Education.

Creswell, J. W. (2012). Educational research: Planning, conducting, and evaluating quantitative and qualitative research (4th ed.). Boston: Pearson.

Delaney, AM. 2009. Institutional researchers' expanding roles: Policy, planning, program evaluation, assessment, and new research methodologies. In $\mathrm{C}$. Leimer (ed.), Imagining the future of institutional research. New Directions for Institutional Research, 143:28-41. http:// dx.doi.org/10.1002/ir.303

Department of Higher Education and Training (DHET). 2014a. Ministerial Statement on University Funding: 2015/16 and 2016/17 (November 2014) [Retrieved 13 May 2015] http://www.dhet.gov. 
za/Financial\%20and\%20Physical\%20 Planning/Ministerial\%20Statement $\% 20$ at\%20University\%20funding;\%20 2015-16\%20and\%202016-2017,\%20 November\%202014.pdf

Department of Higher Education and Training (DHET). 2014b. Policy Framework on Differentiation in the South African PostSchool System. Pretoria, South Africa: Department of Education.

Du Toit, A. 2007. Autonomy as a Social Compact. Research Report 4 Prepared to the CHE Task Team on South African Government Involvement in, and Regulation of Higher Education, Institutional Autonomy and Academic Freedom (HEIAAF). Pretoria: Council on Higher Education.

Ferlie, E., Musselin, C., and Andresani G. 2008. The steering of higher education systems: a public management perspective. Higher Education, 56:325348. http://dx.doi.org/10.1007/s10734008-9125-5

Fuller, B. 1976. A framework for academic planning. The Journal of Higher Education, 47(1):65-77. http://dx.doi. org/10.2307/1978714

Habib, A. 2016. Goals and Means: Some reflections on the 2015 \#FeesMustFall Protests. Daily Maverick [Retrieved 20 June 2016] http://www.dailymaverick. co.za/opinionista/2016-01-26-goals-andmeans-some-reflections-on-the-2015feesmustfall-protests/\#.V2gNj9IrLDc

Hathaway, RS. 1995. Assumptions Underlying Quantitative and Qualitative Research: Implications for Institutional Research. Research in Higher Education, 36(5):535-562. [Retrieved 10 November 2015] http://www.jstor. org/stable/40196253 http://dx.doi. org/10.1007/BF02208830

Higgins, J. 2013. Academic freedom in a democratic South Africa: essays and interviews on higher education and the humanities. Johannesburg: Wits University Press.

Jansen, HAM. 2010. The Logic of Qualitative Survey Research and its Position in the Field of Social Research Methods [63 paragraphs]. Forum Qualitative Sozialforschung / Forum: Qualitative Social Research, 11(2), Art. 11, http:// nbn-resolving.de/urn:nbn:de:0114fqs1002110.

Lange, L., Saavedra, FM. and Romano, J. 2013. Institutional Research in Emerging Countries of Southern Africa, Latin America, and the Middle East and North Africa: Global Frameworks and Local Practices. New Directions for Institutional Research, 13(157):23-38. http://doi. org/10.1002/ir.20037. http://dx.doi. org/10.1002/ir.20037

Leimer, C. 2009. Taking a broader view: Using institutional research's natural qualities for transformation. New Directions for Institutional Research, 143:23-38. http://dx.doi.org/10.1002/ ir.20037

Maassen, PAM. and Potman, HP. 1990. Strategic decision making in higher education: An analysis of the new planning system in Dutch higher education. Higher Education, 20:393410. http://dx.doi.org/10.1007/ BF00136220

McCourt, W. 2002. "New Public Management in developing countries". In McLaughlin, K. Osborne SP. and Ferlie E. New Public Management Current Trends and Future Prospects. Routledge. London and New York. 227-242.

McMillan, J.H. and Schumacher, S., 2010. Research in education: Evidence-based inquiry (7th ed.). New Jersey: Pearson.

Merisotis, JP. and Gilleland, DS. 2000. Funding South African Higher Education: Steering mechanisms to meet national goals. The institute for higher education policy. Washington, DC.

Morest, V.S., 2009. Accountability, accreditation, and continuous improvement: Building a culture of evidence. New Directions for Institutional Research, 2009(143), pp.17-27. http:// dx.doi.org/10.1002/ir.302

National Planning Commission (NPC). 2012. National Development Plan. Pretoria.

Polidano, C. 1999. The new public management in developing countries. IDPM Public Policy and Management Working Paper no. 13 November 1999. Institute for Development Policy and Management University of Manchester Precinct Centre, UK. 
Republic of South Africa (RSA). 1996. Constitution of the Republic of South Africa Act. Government Gazette. December.

Republic of South Africa (RSA). 1997a. Education White Paper 3. A programme for the transformation of higher education. Government Gazette General Notice 1196 of 1997. Pretoria, South Africa: Department of Education.

Republic of South Africa (RSA). 1997b. Higher Education Act. Government Gazette. November.

Republic of South Africa (RSA). 2001. National Plan for Higher Education. Pretoria, South Africa: Department of Education. March

Republic of South Africa (RSA). 2003. Funding of Public Higher Education. Government Gazette, No. 25824 of 9 December 2003. Pretoria, South Africa: Department of Education.

Republic of South Africa (RSA). 2008. National Qualifications Framework Act. Cape Town: Government Gazette. February.

Republic of South Africa (RSA). 2014a Higher Education Qualifications Sub-Framework. Government Gazette General Notice 38116 of 2014. Pretoria, South Africa: Department of Education.

Republic of South Africa (RSA). 2014b. The White Paper for Post-School Education and Training. Pretoria, South Africa: Department of Education.

Republic of South Africa (RSA), 2015a. Higher Education Amendment Bill B36-2015. ISBN 978-1-4850-0275-8. Government Printing Works. Cape Town, South Africa

Republic of South Africa (RSA). 2015b. Skills Development Act, 1998 (Act No. 97 Of 1998): A Call for Public Comments on the Document Titled "Proposal For The New National Skills Development Strategy (NSDS) And Sector Education And Training Authorities (SETAs) Landscape with in the Context of an Integrated and Differentiated Post-School Education And Training System (NSLP2015)". Government Notice 1088, Pretoria, South Africa: Department of Education.
Roberts-Holmes, G., 2014. Doing your early years research project: A step by step guide. London: Sage.

Salmi, J. 2012. Unleashing the Potential of South African Universities: Assessing the Tertiary Education Ecosystem. Centre of Higher Education Transformation (CHET). November http://chet.org. za/files/Salmi\%202012\%20SA\%20 Tertiary\%20Education\%20Ecosystem.pdf

Saupe, J. 1990. The functions of institutional research (2nd ed.). Tallahassee, FL: Association of Institutional Research.

Seymour, D. 2002. Linking planning, quality improvement and Institutional Research: Los Angeles City College. 116(Fall):59-69.

Taylor, J., Hanlon, M. and Yorke, M. 2013. The Evolution and practice of institutional research. New Directions for Institutional Research. 157(Spring):59-75. http://dx.doi.org/10.1002/ir.20039

Terenzini, PT. 1993. On the nature of institutional research and the knowledge and skills it requires. Research in Higher Education, 34(1):1-10. http://dx.doi. org/10.1007/BF00991859

Treuthardt, L. and Välimaa, J. 2008. Analysing Finnish steering system from the perspective of social space: the case of the "Campus University". High Education (2008) 55:607-622. http:// dx.doi.org/10.1007/s10734-007-9078-0

Toma, JD. 2008. A few reflections on accountability, affordability, and access worldwide. New Directions for Institutional Research. http://dx.doi. org/10.1002/ir.281

Volkwein, JF. 2010. A model for assessing institutional effectiveness. New Directions for Institutional Research. Spring:13-28 http://dx.doi.org/10.1002/ ir.328

Voorhees, RA. 2005. "Institutional Research and New Program Development." In RA. Voorhees and Voorhees and L. Harvey (eds.), Workforce Development and Higher Education: A Strategic Role for Institutional Research. New Directions for Institutional Research, no. 128. San Francisco: Jossey-Bass. http://dx.doi. org/10.1002/ir.161 